\title{
Europa en de wereld: de eeuwige machtsvraag
}

Citation for published version (APA):

Orbie, J., \& Vanhoonacker, S. M. R. L. (2008). Europa en de wereld: de eeuwige machtsvraag. Res Publica: politiek-wetenschappelijk tijdschrift van de Lage Landen, 50, 85-98.

https://doi.org/10.5553/RP/048647002008050002001

Document status and date:

Published: 01/01/2008

DOI:

10.5553/RP/048647002008050002001

Document Version:

Publisher's PDF, also known as Version of record

Document license:

Taverne

Please check the document version of this publication:

- A submitted manuscript is the version of the article upon submission and before peer-review. There can be important differences between the submitted version and the official published version of record.

People interested in the research are advised to contact the author for the final version of the publication, or visit the DOI to the publisher's website.

- The final author version and the galley proof are versions of the publication after peer review.

- The final published version features the final layout of the paper including the volume, issue and page numbers.

Link to publication

\footnotetext{
General rights Owners
rights.

- You may freely distribute the URL identifying the publication in the public portal. please follow below link for the End User Agreement:

www.umlib.nl/taverne-license

Take down policy

If you believe that this document breaches copyright please contact us at:

repository@maastrichtuniversity.nl

providing details and we will investigate your claim.
}

Copyright and moral rights for the publications made accessible in the public portal are retained by the authors and/or other copyright owners and it is a condition of accessing publications that users recognise and abide by the legal requirements associated with these

- Users may download and print one copy of any publication from the public portal for the purpose of private study or research.

- You may not further distribute the material or use it for any profit-making activity or commercial gain

If the publication is distributed under the terms of Article $25 \mathrm{fa}$ of the Dutch Copyright Act, indicated by the "Taverne" license above, 


\title{
Europa en de wereld: de eeuwige machtsvraag
}

Jan Orbie en Sophie Vanhoonacker ${ }^{1}$

\begin{abstract}
This introductory article situates the three contributions to this special issue on 'Europe and the world' within the broader academic discussion on the European Union's (EU) international role. It expands on the two central questions that run as a red line through this issue: what is the role and power of EU level players in the external policymaking process; what kind of power is Europe in the world? The first part focuses on the explanatory power of rational choice theories and more particularly the principal-agent model when trying to understand the power struggle between the European and national level. The second part addresses the question whether the EU constitutes a sui generis type of international actor, as suggested by the Normative Power Europe hypothesis. With the articles in this special issue as a starting point, it points to the promises and pitfalls of the particular approaches for researching Europe's international role and makes suggestions for future research. KEYWORDS: European Union; EU External Policies; Common Foreign and Security Policy (CFSP); Principal-Agent; Normative Power Europe
\end{abstract}

De ontwikkeling van het externe optreden van de Europese Unie (EU) laat zich niet makkelijk vatten. Het is een geschiedenis met meerdere verhaallijnen die nog volop wordt geschreven. Terwijl een gemeenschappelijk handelsbeleid en ontwikkelingssamenwerking reeds meer dan een halve eeuw op de Europese agenda staan, is de samenwerking op het gebied van buitenlands beleid recenter en werd deze aanvankelijk buiten het kader van de Europese Gemeenschap (EG) georganiseerd. Sinds het verdrag van Maastricht (1993) is het Gemeenschappelijk Buitenlands en Veiligheidsbeleid (GBVB) echter met een belangrijke inhaalbeweging bezig en sinds de deelname aan militaire en civiele missies heeft het tevens een operationele dimensie gekregen in het kader van het Europees Veiligheids- en Defensiebeleid (EVDB). Terwijl de lidstaten zich in de jaren '80 nog voornamelijk konden concentreren op het realiseren van de interne markt, is er sinds de val van de Berlijnse muur en de toenemende globalisering steeds meer behoefte om ook naar buiten toe meer met één stem te spreken. In de Verklaring van Laken (december 2001) werd de ontwikkeling van 'een samenhangend en doeltreffend optreden van de 
Unie' tot één van de centrale thema's in het debat over de toekomst van Europa gekatapulteerd. Het Verdrag van Lissabon (december 2007) introduceert wijzigingen zoals een permanente voorzitter van de Raad Buitenlandse Zaken en permanent gestructureerde veiligheidssamenwerking ${ }^{2}$ die de EU extern meer slagkracht moeten geven. Nieuwe uitdagingen op het internationale politieke toneel - klimaat, energie, terrorisme, China, migratie, humanitaire rampen - vragen steeds meer om een antwoord op EU-niveau. Bovendien wordt de ontwikkeling van een sterker geïntegreerd Europees buitenlands beleid ook door een groot deel van de Europese bevolking ondersteund. ${ }^{3}$

Het feit dat een Europees buitenlands beleid langzaam maar zeker gestalte krijgt is niet alleen uitdagend voor beleidsmakers die over de coherentie van het geheel moeten waken, het geeft ook aanleiding tot nieuwe academische vragen. Naast het belang om nieuw empirisch materiaal te verzamelen, rijst de vraag in welke mate de theoretische handvatten aangereikt vanuit de internationale betrekkingen, vergelijkende politicologie en klassieke integratietheorieën bijdragen tot een beter begrip van de internationale rol van de EU. Aangezien de verschillende verhaallijnen steeds meer door elkaar heen lopen is het bovendien van belang dat onderzoekers het eendimensionele denken overstijgen en aandacht besteden aan vragen die zich met meer dan alleen handel of GBVB-kwesties bezighouden. Het politicologisch onderzoek over het internationale optreden van de EU weerspiegelt namelijk de historisch gegroeide compartementalisatie in de EU-politiek. Binnen de academische wereld bestaan nog altijd hoge muren tussen onderzoekers die de internationale dimensie van het 'eerste pijler'-beleid van de EU (zoals onder meer handelspolitiek, ontwikkelingsbeleid, milieubeleid) bestuderen, en zij die de 'tweede pijler' van het GBVB analyseren. Bovendien gaat het vaak om beschrijvende casestudies eerder dan om theoretisch ingebedde bijdragen.

Steeds meer academici en politici gaan echter op zoek naar een geïntegreerd verhaal over de rol van Europa in de wereld. Twee vragen staan hierbij centraal: wie heeft macht in Europa, en wat voor macht is de EU?

De bovengenoemde recente ontwikkelingen en de nieuwe onderzoeksuitdagingen zijn voor de redactie van Res Publica de aanleiding om een speciaal themanummer te wijden aan de internationale rol van de EU. Hierbij wordt ernaar gestreefd om zowel aandacht te besteden aan de verschillende deelaspecten als aan het totaalbeeld. Bovendien werden de artikelen ook geselecteerd op basis van hun bijdrage aan het politicologische debat. Enerzijds blijkt de tweedeling in de studie naar Europees extern beleid ook uit de gepubliceerde bijdragen. Het artikel van Tom Delreux biedt een casestudie uit de eerste pijler en gaat in op de rol van de EU in internationale milieuonderhandelingen. De bijdragen van Hylke Dijkstra en Sven 
Biscop/Alexander Mattelaer richten zich op de tweede pijler, met casestudies over respectievelijk de Brusselse besluitvorming in het GBVB en de operatie European Union Force (EUFOR) in Tsjaad en de Centraal Afrikaanse Republiek (CAR). Anderzijds overstijgen de bijdragen het beschrijvende door hun meer theoretische aanpak, waarbij ze de machtsverhoudingen binnen de EU en de aard van Europa's macht op wereldvlak analyseren.

In deze introductie gaan we in op de vragen die in de verschillende bijdragen aan de orde worden gesteld en situeren we deze in het bredere debat over de EU als een internationale speler. Bovendien worden mogelijke dwarsverbanden geëxploreerd en wordt indien relevant een link gelegd naar de toekomstige ontwikkeling van Europa's rol op de internationale scène.

\section{Wie heeft macht in Europa?}

De vraag naar de respectievelijke rol van de lidstaten en supranationale actoren in integratieprocessen is een kwestie die ook reeds integratietheoretici van het eerste uur volop bezighield. Terwijl neofunctionalisten (Haas, 1958; Øhrgaard, 2004; Niemann, 2006) de rol van de supranationale Commissie als een bepalende motor van integratie identificeren, benadrukken (liberale) intergouvernementalisten de sleutelrol van de lidstaten (Hoffmann, 1966; Moravcsik, 1998). Voor deze laatste zijn het in eerste instantie de nationale hoofdsteden die de mate van autonomie van het supranationale niveau bepalen. Gedurende lange tijd concentreerde de discussie tussen beide groepen zich vooral op de sleutelmomenten in het Europese integratieproces. Aangezien er tot de val van de Berlijnse Muur nauwelijks vooruitgang werd gemaakt met samenwerking op het gebied van buitenlands beleid, richtte het debat zich op het beter begrijpen en verklaren van economische integratie. Na het mislukken van de supranationale Europese Defensiegemeenschap (1954) en met de organisatie van Europese Politieke Samenwerking (EPS) (1970-1993) op een intergouvernementele leest was de vraag naar de rol van een supranationale actor zoals de Europese Commissie simpelweg niet aan de orde. Samenwerking op het vlak van buitenlands beleid bleek een andere logica te volgen dan het economische integratieproces. Voor lange tijd was het überhaupt de vraag of de EU kon beschouwd worden als een volwaardige internationale actor. De beperkte politieke wil van de lidstaten, het gebrek aan cohesie, en het feit dat derde landen vaak de nationale hoofdsteden veeleer dan Brussel als gesprekspartner verkozen waren voor velen afdoende redenen om de vraag negatief te beantwoorden (Sjöstedt, 1977). De afhankelijkheid van de Amerikaanse veiligheidsparaplu deed bovendien ernstige twijfels rijzen over de capaciteit om uit te groeien tot een autonome internationale actor (Bull, 1982). 
Terwijl de klassieke integratietheorieën vooral geïnteresseerd zijn in een beter begrip van de historische integratiemomenten, is er sinds halfweg de jaren '90 ook meer aandacht voor de dagelijkse besluitvorming. De vraag naar de machtsverhoudingen tussen de Europese lidstaten en het supranationale niveau blijft aan de orde, maar meer bescheiden en afgebakend. Met name het neo-institutionalisme met zijn historische, sociologische en rationele keuzevariant, stelt de vraag hoe supranationale actoren zoals de Europese Commissie in bepaalde omstandigheden (naargelang het beleidsdomein, besluitvormingsregels, internationale context, specifieke bureaucratieën en agentschappen) invloed uitoefenen op de voorkeur en het gedrag van lidstaten. Vanuit de vraag of de EU daadwerkelijk een autonome internationale speler is, zijn ook onderzoekers op het gebied van EU extern beleid zich voor deze kwestie gaan interesseren (Nicolaïdis, 1999; Meunier en Nicolaïdis, 2000; Kerremans, 2004; M.E. Smith, 2004; Versluys, 2007).

De eerste twee bijdragen in dit themanummer situeren zich binnen de neo-institutionalistische traditie en gaan uit van een rationeel institutionalistisch perspectief dat lidstaten beschouwt als rationele actoren die hun belangen maximaal proberen te realiseren. Zowel Delreux als Dijkstra onderzoeken de rol van het Europese niveau in het externe EU-beleid en maken gebruik van het principal-agent-model waarbij de lidstaten als 'principals' bepaalde taken delegeren aan 'agents' op Europees niveau. Delreux onderzoekt de onderhandelingsautonomie van de EU in internationale milieuonderhandelingen; Dijkstra concentreert zich op de rol van supranationale actoren in het GBVB-besluitvormingsproces. In tegenstelling tot het handelsbeleid gaat het in beide gevallen niet om een exclusieve competentie. De lidstaten vervullen een centrale rol. Dit betekent dat naast de Commissie ook agenten vanuit de Raad zoals het Voorzitterschap, 'lead countries' en het Raadssecretariaat (RSG) optreden. De hamvraag is in welke mate deze 'agenten' die door de lidstaten worden aangesteld om het onderhandelings- en besluitvormingsproces te faciliteren, een eigen impact hebben en hoe bewerkstelligd kan worden dat zij handelen in overeenstemming met de nationale preferenties.

Een van de grootste lacunes in het onderzoek naar de invloed van Europese instellingen is het gebrek aan empirische studies die een inzicht geven in de variabelen die de mate van autonomie van deze spelers bepalen. Een dergelijk onderzoek is een absolute vereiste om meer theoretisch onderbouwde modellen over invloed van supranationale actoren te ontwikkelen. Het is dan ook een grote verdienste van Delreux dat hij aan de hand van een uitgebreid en diepgaand casestudieonderzoek over internationale milieuonderhandelingen de factoren die de onderhandelingsautonomie van spelers zoals de Europese Commissie of het Voorzitterschap bepalen identificeert. Zijn analyse laat zien dat de dwingendheid van de externe onderhandelingscontext een belangrijke verklaring is voor de mate van autonomie 
van de Europese onderhandelaar. De autonomie blijkt klein in een weinig dwingende internationale context; omgekeerd kan de agent de externe dwingendheid exploiteren om meer autonomie te verkrijgen. Andere factoren die een rol spelen zijn de mate van institutionele dichtheid, heterogene preferenties tussen lidstaten en traditionele principal-agent-factoren zoals informatieasymmetrieën en preferentieafstanden.

De vraag die zich onmiddellijk opdringt is in welke mate deze inzichten ook van toepassing zijn op andere beleidsdomeinen. Hiervoor is verder vergelijkend onderzoek noodzakelijk. Hoewel men zich kan voorstellen dat zijn analyse, zoals Delreux zelf suggereert, ook bevindingen genereert voor andere beleidsdomeinen met een externe dimensie zoals handel, visserij, mededinging, is dit minder vanzelfsprekend voor het intergouvernementele GBVB. Een dwingende externe situatie zoals de nakende oorlog in Irak (2003) bleek veeleer de autonomie van Europese actoren zoals bijvoorbeeld de Hoge Vertegenwoordiger voor het GBVB te verkleinen. Ook in andere opzichten blijkt een verschil met de tweede pijler. In de eerste plaats zijn de formele bevoegdheden van de Commissie veel beperkter. Verder blijkt uit de bijdrage van Dijkstra dat de terughoudendheid om meer taken te delegeren aan Brussel nog steeds bijzonder groot is. Het resultaat is dat de lidstaten een grote creativiteit aan de dag leggen bij het bedenken van controlemechanismen. Dit gebeurt onder meer door de verantwoordelijkheden voor de formulering en de uitvoering van het GBVB te verdelen over de Commissie en het RSG. Bovendien hebben de lidstaten ervoor geopteerd om een belangrijk deel van de nieuwe posten in het RSG te bemannen met gedetacheerde diplomaten. Dit geeft hen een directe en geprivilegieerde toegang tot wat in Brussel gebeurt. Toch neemt dit niet weg dat er ook op het gevoelige domein van buitenlands beleid, voor supranationale actoren een zekere ruimte is om autonoom op te treden en invloed uit te oefenen. Uit Dijkstra's historische beschrijving van de groeiende buitenlandrol van de Commissie en het RSG, blijkt dat vooral hun kennis van beleidsprocedures en inhoudelijke expertise fungeren als een bron van invloed. Verder empirisch onderzoek moet nog uitmaken onder welke condities deze expertise zich vertaalt in concrete invloed.

De verschillende bevindingen met betrekking tot beide pijlers nemen niet weg dat voor zowel de internationale milieuonderhandelingen als het GBVB het principalagent-model een interessante lens biedt om tot een beter begrip te komen van de mate van autonomie van Europese actoren. Het bijzondere karakter van het GBVB staat de toepassing van het model niet in de weg. Een van de keerzijden van een pure rational choice-benadering is echter dat deze weinig oog heeft voor de impact van institutionele normen en processen van socialisatie. Zeker in een sterk geïnstitutionaliseerde omgeving als de EU valt te verwachten dat deze factoren van belang zijn (Checkel, 2007; Bátora, 2005; Glarbo, 1999). Delreux probeert 
deze lacune te adresseren door ook de impact van de institutionele dichtheid mee te nemen in zijn studie. Hij constateert een positief verband tussen de mate van institutionele dichtheid en de autonomie van de EU-onderhandelaar als ook aan een aantal andere voorwaarden met betrekking tot het besluitvormingsproces is voldaan. De vraag geldt ook voor het GBVB. Met het Europees Veiligheids- en Defensiebeleid en nieuwe permanente Brusselse structuren zoals het Politiek en Veiligheidscomité is de institutionele dichtheid sterk toegenomen. Ook al was de institutionele omgeving op het gebied van buitenlands beleid lange tijd weinig ontwikkeld, toch was er ook reeds ten tijde van EPS sprake van een toenemende coördinatiereflex tussen de participerende diplomaten. Het valt te verwachten dat deze trend zich na Lissabon met de oprichting van een Europese Dienst voor Extern Optreden verder zal zetten. Het lijkt ons dan ook belangrijk om dit stuk van de puzzel verder te onderzoeken en de inzichten vanuit het rationeel institutioneel perspectief te confronteren met die uit andere theoretische invalshoeken, zeker wanneer het maximeren van nationale belangen slechts een deel van het besluitvormingsproces of de uitkomst kunnen verklaren.

\section{Wat voor macht is Europa?}

Een andere vraag die recentelijk veel opgang maakt in het politiek-wetenschappelijk onderzoek gaat over de aard van Europa's internationale macht: kunnen we de EU beschouwen als een macht apart? De nadruk ligt hier minder op het interne machtsevenwicht binnen en tussen de EU-instellingen, maar eerder op het zogenaamde unieke karakter van de Unie op de internationale scène. Theoretisch weerspiegelt deze stroming grotendeels de constructivist turn in de EU-studies (Christiansen et al., 2001) en in de studie van het Europees buitenlands beleid (Manners en Whitman, 2000, pp. 4-6), waarbij de impact van normen, waarden, identiteit en discours onderzocht wordt.

Het academische debat over het specifieke karakter van de EG in de wereldpolitiek gaat evenwel terug tot de jaren '70. Hierbij focuste men vooral op de afwezigheid van een Europese defensiecapaciteit. De EG werd beschouwd als een 'civiele macht' (Duchêne, 1973), die internationale doelstellingen zoals mensenrechten, democratie en solidariteit nastreeft via een breed arsenaal aan 'civiele' instrumenten zoals handelsrelaties, ontwikkelingshulp, partnerschappen, politieke dialoog en multilaterale instellingen. Dankzij de afwezigheid van militaire macht zou Europa een unieke rol spelen op de internationale scène.

Het idee van Europa als civiele macht blijft tot vandaag dominant in het politicologische debat en in het politieke discours (Sjursen, 2006; Orbie, 2008). De kritiek 
vanuit realistische hoek luidt echter dat de EU geen internationale rol van betekenis kan spelen zonder militaire middelen. Zij zien het civiele machtsdenken als een poging om de Europese onmacht te verhullen in een ethisch discours. Europa is in het beste geval een civiele macht by default (Bull, 1982; Kagan, 2004). Wanneer de EU eind jaren '90 een defensiecapaciteit ging uitbouwen, ontstond dan weer een debat over de wenselijkheid van militaire middelen op EU-niveau. Sommigen beschouwden dit als de doodsteek van de Europese identiteit als civiele, niet-traditionele macht (Smith, 2000), maar de meeste academici (en Europese politici) betoogden dat een militaire arm de slagkracht en geloofwaardigheid van de EU om normatieve doelstellingen te verspreiden alleen maar zou vergroten (Stavridis, 2001).

Hiermee verschoof de focus van Europa's externe machtsmiddelen naar de doelstellingen die ze wil nastreven in de wereld. De term 'normatieve macht' werd in toenemende mate verkozen boven die van civiele macht. Het artikel van Ian Manners over Normative Power Europe gaf aanleiding tot een uitvoerige en diepgaande academische discussie ${ }^{4}$ over de vraag of de EU een unieke normatieve of ethische rol speelt in de wereld. Omwille van Europa's specifieke geschiedenis, haar politiek-juridische constitutie en haar 'post-moderne' bestuursvorm zou de Unie bij uitstek goed uitgerust zijn om Europese ‘basis-normen’ zoals vrijheid, democratie, mensenrechten en fundamentele vrijheden, en de rechtsstaat te verspreiden in de wereld (Manners, 2002). Europa doet dit niet via fysieke macht maar via meer subtiele kanalen, zoals onder meer culturele verspreiding. Daarom stelt Manners dat "the most important factor shaping the international role of the EU is not what it does or what it says, but what it is" (Manners, 2006, p. 184). ${ }^{5}$

Een kritiek op deze nieuwe onderzoeksagenda in de EU-literatuur betreft de assumptie van het sui generis-karakter van de EU. Door de presentatie van de EU als een unieke en normatieve macht wordt een beeld geconstrueerd dat niet onschuldig is, maar dat de legitimiteit van het Europese project vergroot. ${ }^{6}$ Hierbij wordt de postmoderne en ethische buitenlandse agenda van de EU gecontrasteerd met de klassieke grootmachtpolitiek van de VS. Nochtans streeft de Unie in haar internationale optreden evengoed economische en geostrategische belangen na (Youngs, 2004), terwijl andere actoren zoals de VS, China, India of Rusland ook de nadruk kunnen leggen op normatieve doelstellingen in hun buitenlands beleid (Diez, 2005; Tocci, 2007).

De normatieve dimensie van Europa's internationaal optreden wordt ook vanuit een meer rationalistische invalshoek bestudeerd. Jan Zielonka (2006) ging na hoe de EU haar eigen 'model' - inclusief waarden zoals democratie en mensenrechten, regelgeving op het gebied van milieu, arbeid en voedselstandaarden - exporteert naar andere landen en regio's. Hij benadrukt dat Europa gebruikmaakt van harde 
economische instrumenten (niet enkel soft power en overtuiging) en dat economische belangen hierbij vooropstaan (niet zomaar normatieve doelstellingen). Op die manier kan Europa een aanzienlijke macht uitoefenen op de internationale scène. Toch vormt Europa geen klassieke staat: de Unie is eerder een polycentrische entiteit zonder duidelijke geografische en bevoegdheidsafbakeningen, en zonder duidelijk centrum van autoriteit. Daarom formuleert Zielonka een alternatief rolconcept: de EU als nieuw-middeleeuws imperium (zie ook de boekbespreking van Jan Beyers verder in dit nummer).

De Unie tracht namelijk haar eigen normen op te leggen aan niet-Europese landen. Dit blijkt in eerste instantie uit de uitbreidingspolitiek tegenover Centraal- en OostEuropa en het nabuurschapsbeleid tegenover de nieuwe buren in het oosten en zuiden van Europa. Maar ook op mondiaal vlak toont de EU zich een assertieve speler die binnenlandspolitieke regels in derde landen poogt te beïnvloeden, onder meer via handelsakkoorden. Hoewel de EU om economische en politieke redenen gedwongen is om haar eigen normen te promoten buiten de onmiddellijke omgeving, twijfelt Zielonka of zij hierin zal slagen. Hij wijst erop dat er vanuit landen zoals China, India of Brazilië steeds meer verzet komt tegen de verspreiding van het 'Europese model'.

Ook in hun bijdrage aan dit themanummer onderzoeken Biscop en Mattelaer de aard van de EU als internationale actor en de rol van normatieve doelstellingen in de buitenlandstrategie van de EU. Meer bepaald peilen ze naar de ontwikkeling van een collectieve 'strategische cultuur' op EU-niveau. De 'Europese manier' om buitenlandspolitieke problemen aan te pakken is weergegeven in de Europese Veiligheidsstrategie (EVS) (december 2003), die in feite een buitenland-, veeleer dan een veiligheidsstrategie is. De EVS omhelst een geïntegreerde visie op de doelstellingen die Europa nastreeft (een langetermijnbeleid van stabilisering en preventie, gericht op de bevordering van mondiale publieke goederen) en op de middelen die hiervoor ingezet worden (een geïntegreerde civiel-militaire aanpak).

Maar aangezien de Europese strategische gemeenschap zeer heterogeen is - zoals de bijdrage van Dijkstra aantoont omvat ze de lidstaten en diverse administraties op Raads- en Commissieniveau - verloopt de ontwikkeling van een Europese strategische cultuur langzaam. De nieuwe Europese consensus ziet militaire middelen als een ultiem instrument. Het kan enkel aangewend worden onder mandaat van de Veiligheidsraad, wanneer het volledige gamma van andere instrumenten uitgeput is, en met de bedoeling om normatieve buitenlandspolitieke doelstellingen (zoals de naleving van mensenrechten) te bevorderen. Maar over het gebruik van militair geweld - waar, hoe, en wanneer - blijven meningsverschillen tussen de EU-lidstaten de kop opsteken. 
Dus hoewel Europese beleidsmakers de civiele machtsrol verzoend hebben met de ontwikkeling van een defensieluik op EU-niveau (Larsen, 2002), bestaat er nog geen consensus over het concrete gebruik van militair geweld. In ieder geval vormt de EU nog lang geen militaire macht van betekenis, en het is onzeker of zij dit ooit wel zal worden. Dit betekent dat het gebruik van niet-militaire machtsmiddelen, gaande van economische sancties tot diplomatieke dialoog en overtuiging, een overheersend kenmerk van het internationale optreden van de EU zal blijven. Wat echter niet betekent dat de EU meteen ook een sui generis-constructie is die uitblinkt door haar civiele of normatieve karakter en daarmee aan de wetten van de politicologie ontsnapt.

Een verdienste van Biscops en Mattelaers artikel is dat de auteurs de discussie over de aard van de EU op wereldvlak empirisch onderzoeken. Academische debatten over de EU als civiele/normatieve macht zijn vaak in theoretische termen gevoerd, of doorspekt met anekdotisch bewijsmateriaal, terwijl een grondige empirische ondersteuning vaak achterwege blijft (cf. Sjursen, 2006, p. 177). Biscop en Mattelaer koppelen beide dimensies in hun onderzoek naar het Europese optreden in de operatie EUFOR in Tsjaad en de CAR. Net als de andere militaire operaties onder EU-vlag die sinds 2003 plaatsvonden, affirmeert de Unie zich hier 'als een strategische actor met een eigen identiteit'. De gevalstudie toont echter ook de pijnpunten in de geïntegreerde benadering van het EU-beleid. Mede door het gebrek aan een militaire deelstrategie (zie hoger) slaagt Frankrijk erin om een dominante rol te spelen in de missie, wat de neutraliteit van de EU in het gedrang brengt.

Of en in welke mate het effectief gaat om een sui generis-buitenlandstrategie van de EU valt buiten de onderzoeksopzet van het artikel. De auteurs stippen aan dat er zich een strategische cultuur ontwikkelt op EU-niveau, die onderscheiden is van de lidstaten. Bovendien zou de EU haar geïntegreerde visie op veiligheid met succes exporteren naar andere organisaties zoals de NAVO. Maar Biscop en Mattelaer wijzen ook op de overeenkomsten tussen de EU-consensus en het concept van human security, dat al langer opgang maakte in de VN en in landen als Canada en Japan. Verder onderzoek naar de EU-visies, toegepast op verschillende gevalstudies, zou meer precies kunnen aantonen waarin de Europese strategische cultuur (in wording) precies verschilt van andere internationale actoren, in welke mate de EU haar buitenlandspolitieke normen importeert of exporteert, en wat de dynamieken zijn achter deze processen die vormgeven aan het internationale karakter van de EU.

\section{Conclusie}

De bedoeling van een themanummer is meestal om een bepaald onderwerp in de kijker te zetten en bij te dragen tot de algemene academische discussie. Alhoewel 
het van te voren onduidelijk is welke bijdragen aangeleverd en geselecteerd worden, pakt zo'n nummer het beste uit wanneer het erin slaagt een beeld te geven van de onderzoeksvragen die op dat moment aan de orde zijn en diversiteit weet te combineren met een zekere samenhang. Hoewel de artikels in dit nummer op zichzelf staan en met diverse onderwerpen bezig zijn, hebben we in deze inleidende bijdrage gepoogd om stil te staan bij wat hun bundeling als meerwaarde biedt en na te gaan in welke mate ze iets leren over het huidige debat. Drie punten kunnen hierbij worden aangestipt.

In eerste instantie illustreert dit nummer dat de dubbele ontwikkeling in het externe EU-optreden, waarbij verschillende dimensies naar mekaar toegroeien maar tegelijkertijd ook hun eigenheid behouden, ook terug te vinden is in het academische debat. Enerzijds richt een deel van het onderzoek zich nog altijd op vragen die zich beperken tot een bepaald aspect van de internationale rol van de EU zoals het GBVB, milieuonderhandelingen en militaire operaties, anderzijds wordt ook in toenemende mate aandacht besteed aan het externe beleid in zijn totaliteit.

Ten tweede tonen de bijdragen het belang van de klassieke machtsvraag. Terwijl onderzoekers die zich concentreren op een deelaspect van het internationale EUoptreden vooral bezig zijn met wie binnen de besluitvormingsdynamiek aan de touwtjes trekt, is de tweede groep vooral geïnteresseerd in de aard van de Europese macht. De bijdragen van Delreux en Dijkstra enerzijds en Biscop / Mattelaer anderzijds tonen echter dat definitieve conclusies voorbarig zijn. Dit heeft niet alleen te maken met het feit dat meer empirisch onderzoek nodig is om bepaalde hypothesen met betrekking tot handelingsautonomie of normatieve macht verder te testen en resultaten te vergelijken, maar is ook gerelateerd aan het nog in volle ontwikkeling zijn van het externe EU-beleid.

Verder bieden de bijdragen ook een interessante opening naar het debat over het sui generis-karakter van de EU. Zoals blijkt uit de artikels van Delreux en Dijkstra gebaseerd op het principal-agent-model, wordt sinds de algemene erkenning van de EU als een internationale actor in toenemende mate teruggegrepen naar theorieën uit de klassieke politicologie. De relevantie van hun rationeel-institutionalistische benadering voor een beter begrip van de handelingsautonomie van supranationale actoren lijkt erop te wijzen dat de stelling dat de EU zo uniek zou zijn dat ze ontsnapt aan de klassieke wetten van de politiek overdreven is. Anderzijds laten Biscop en Mattelaer zien dat algemene concepten zoals strategische cultuur in een heterogene en meerlagige gemeenschap als de EU specifieke uitdagingen met zich meebrengt. Het laatste woord over het al dan niet eigen karakter van het Europese externe optreden is dus nog niet gevallen. 
Zoals te verwachten komt dit nummer niet tot eenduidige conclusies over de politieke dynamiek achter het internationale EU-optreden. Deze is te complex om herleid te worden tot een enkele vraag of verklaring. Dit themanummer laat niet alleen zien dat er nog een lange weg is af te leggen. Het illustreert ook dat onderzoekers de veelheid aan vragen op een creatieve manier benaderen en door het externe EU-optreden te koppelen aan algemene theorieën en inzichten tot interessante en vernieuwende resultaten komen.

\section{Noten}

1. Jan Orbie is docent aan het Centrum voor EU-Studies van de Universiteit Gent en Sophie Vanhoonacker is bijzonder hoogleraar 'Administrative Governance' aan de Universiteit Maastricht.

2. Deze permanent gestructureerde samenwerking voorziet in een nauwere samenwerking op veiligheidsgebied tussen lidstaten die over de vereiste militaire capaciteiten beschikken.

3. Volgens een opiniepeiling van Eurobarometer (European Commission, 2007, p. 28) vindt $67 \%$ van de ondervraagden dat beslissingen inzake defensie en buitenlandse zaken meer op EU-niveau moeten worden genomen. Dit in tegenstelling tot andere beleidsterreinen zoals het landbouwbeleid en economie waar respectievelijk slechts $53 \%$ en $48 \%$ een sterkere rol van de EU ondersteunt. De bevindingen van Eurobarometer worden ook bevestigd door onderzoek van het German Marshall Fund (2007, p. 13). Dit stelt dat $88 \%$ van de Europeanen voorstander is van een grotere EU-verantwoordelijkheid in het bestrijden van globale dreigingen via ontwikkelingshulp, handel en vredesmissies.

4. Zie bijvoorbeeld het recente themanummer in International Affairs 2008, 84 (1); het debat tussen Ian Manners en Thomas Diez in Millennium - Journal of International Studies, 2005, 33 (3) en 2006, 35 (1).

5. Ook gerespecteerde filosofen als Habermas en Derrida (2003) lijken zich aan te sluiten bij deze denkpiste. Ze benadrukken Europa's unieke model van postnationale governance en sociale solidariteit - iets wat de EU hopelijk kan exporteren naar de rest van de wereld. Daarnaast is er ook een stroom aan recente, meer gepopulariseerde werken die de EU 'bejubelen' als een nieuw soort supermacht (zie de boekbespreking van Jan Beyers in dit nummer). 
6. Zie bijvoorbeeld het interview met Barroso op p. 4: http://www.eu-consent.net/ library/BARROSO-transcript.pdf.

\section{Bibliografie}

Allen, D. (1998). Who Speaks for Europe? The Search for an Effective and Coherent External Policy. In J. Peterson \& H. Sjursen (Eds.), A Common Foreign Policy for Europe? Competing Visions of the CFSP (pp. 41-58). London: Routledge.

Bátora, J. (2005). Does the European Union Transform the Institution of Diplomacy? Journal of European Public Policy, 12 (1), 44-66.

Bull, H. (1982). Civilian Power Europe: A Contradiction in Terms? Journal of Common Market Studies, 12 (2), 149-164.

Checkel, J. (2007). International Institutions and Socialization in Europe. Cambridge: Cambridge University Press.

Christiansen, T., Jörgensen, K.E., \& Weiner, A. (2001) (Eds.). The Social Construction of Europe. London: Sage.

Diez, T. (2005). Constructing the Self and Changing Others: Reconsidering "Normative Power Europe”. Millennium, 33 (3), 613-636.

Duchêne, F. (1973). The European Community and the Uncertainties of Interdependence. In M. Kohnstamm \& W. Hager (Eds.), A Nation Writ Large? Foreign-Policy Problems before the EC (pp. 1-21). London: Macmillan.

European Commission (2007). Public Opinion in the European Union. Eurobarometer No. 68, First Results, December. Online beschikbaar op http://ec.europa.eu/public_opinion/index_en.htm.

German Marshall Fund (2007). Transatlantic trends: Key findings 2007. Online beschikbaar op http://www.transatlantictrends.org/trends/doc/Transatlantic\%20Trends_ all_0920.pdf.

Glarbo, K. (1999). Wide-Awake Diplomacy: Reconstructing the Common Foreign and Security Policy of the European Union. Journal of European Public Policy, 6 (4), 634-651.

Haas, E. (1958). The Uniting of Europe. Stanford: Stanford University Press.

Habermas, J., \& Derrida, J. (2003). February 15, or what binds Europeans together: A Plea for a Common Foreign Policy, beginning in a core of Europe. Constellations, 10, (3).

Hoffmann, S. (1966). Obstinate or Obsolete? The Fate of the Nation-State and the Case of Western Europe. Daedalus, 95 (3), 862-915.

Kagan, R (2004). Of Paradise and Power: America and Europe in the New World Order. New York: Vintage Books. 
Kerremans, B. (2004). What Went Wrong in Cancun? A Principal-Agent View on the EU's Rationale Towards the Doha Development Round. European Foreign Affairs Review, 9 (3), 363-393.

Larsen, H. (2002). The EU: A Global Military Actor? Cooperation and Conflict, 37 (3), 283-302.

Manners, I. (2002). Normative Power Europe: A Contradiction in Terms? Journal of Common Market Studies, 40 (2), 235-258.

Manners, I. (2006). Normative Power Europe Reconsidered: Beyond the Crossroads. Journal of European Public Policy, 13 (2), 182-199.

Manners, I. \& Whitman, R.G. (2000). The Foreign Policy of EU Member States. Manchester: Manchester University Press.

Meunier, S. \& Nicolaïdis, K. (2000). EU Trade Policy: The Exclusive versus Shared Competence Debate. In M. Smith \& M. Green Cowles (Eds.), The State of the European Union. Risks, Reform, Resistance, and Revival (pp. 325-346). New York: Oxford University Press.

Moravcsik, A. (1998). The Choice for Europe: Social Purpose and State Power from Messina to Maastricht. Ithaca, NY: Cornell University Press.

Nicolaïdis, K. (1999). Minimizing Agency Costs in Two-Level Games. Lessons From the Trade Authority Controversies in the United States and the European Union. In R. Mnookin \& L. Susskind (Eds.), Negotiating on behalf of others (pp. 87-126). London: Sage.

Niemann, A. (2006). Explaining Decisions in the European Union. Cambridge: Cambridge University Press.

Orbie, J. (Ed.) (2008). Europe's Global Role: External Policies of the European Union. Aldershot: Ashgate.

Sjöstedt, G. (1977). The External Role of the European Community. Farnborough: Saxon House.

Sjursen, H. (2006). What Kind of Power? Journal of European Public Policy, 13 (2), 169-181.

Smith, K. (2000). The End of Civilian Power EU: A Welcome Demise or Cause for Concern? The International Spectator, 35 (2), 11-28.

Smith, M.E. (2004). Europe's Foreign and Security Policy. The Institutionalization of Cooperation. Cambridge: Cambridge University Press.

Stavridis, S. (2001). "Militarising” the EU: The Concept of Civilian Power Europe Revisited. The International Spectator, 41 (4), 43-50.

Tocci, N. (2007). Profiling Normative Foreign Policy: The European Union and its Global Partners. Centre for European Policy Studies, CEPS Working Document, 20 December.

Versluys, H. (2007). Explaining Patterns of Delegation in EU Humanitarian Aid Policy. Perspectives, 27 (Summer), 63-84. 
Youngs, R. (2004). Normative Dynamics and Strategic Interests in the EU's External Identity. Journal of Common Market Studies, 42 (2), 415-435.

Zielonka, J. (2006). Europe as Empire: The Nature of the Enlarged EU. Oxford: Oxford University Press. 